\title{
Historein
}

Vol 15, No 2 (2015)

Historein 15/2 (2015)

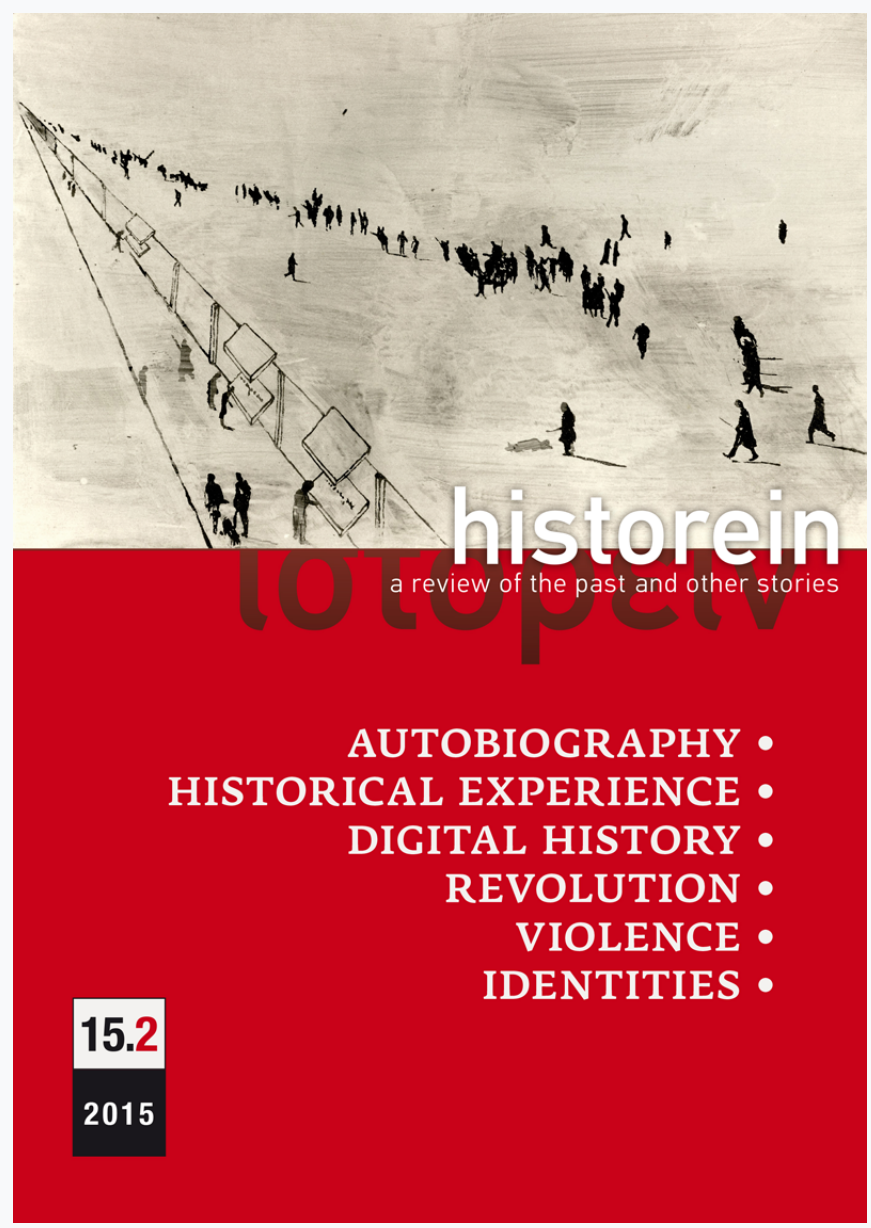

\section{Reconceiving pasts in a digital age}

Stefan Tanaka

doi: $10.12681 /$ historein.8892

Copyright @ 2015, Stefan Tanaka

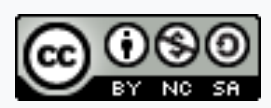

This work is licensed under a Creative Commons Attribution-NonCommercialShareAlike 4.0.

To cite this article:

Tanaka, S. (2016). Reconceiving pasts in a digital age. Historein, 15(2), 21-29. https://doi.org/10.12681/historein.8892 
Digital media began to enter historical practices around the end of the twentieth century. ${ }^{1}$ Yet I see this as an article about twentieth-century historiography in several oblique ways. First when the digital first appeared, technophiles were boasting of revolutionary changes and Luddites (like me) were worried about its effect on historical practices. These poles remain. Today, we are someplace in the middle; the digital has often become a tool that enhances existing ways of doing and knowing - more information and storage, faster access and endless editing. More worrisome is the regular shredding of electronic data and a noticeable flattening of time. For example, news feeds are often shorn of dates (windows "of related interest" often mine for similar events regardless of date) and sites compete for rapid dissemination rather than accuracy and context. Moreover, the search, the fulfilment of immediate desire, locks us in the forever present. We are not only more habituated toward immediate gratification, but the retrieval of material is based on algorithms that connect our past habits with that of others to predict desires. This presentism, as François Hartog has also pointed out, extends to politics and economics. He reminds us that this presentism does not have a necessary relation to the digital realm. ${ }^{2}$

My entry into digital media and history came in a discussion on how digital technologies will transform scholarly publishing. At that time it was a straightforward concern of replacement, that electronic media would lead to a decline in traditional print monographs and journals. Now, I prefer to see it as an opportunity to take control of a system that is currently broken. This brings out the second connection to twentieth-century historiography, "O'Donnell's law."

\section{Reconceiving pasts in a digital age}

\section{Stefan Tanaka}

University of California, San Diego 
In a wide-ranging conversation Dan O'Donnell stated, "The novel and non-trivial application of computation to humanities research problems inevitably requires an examination of first principles including the social, political, economic, and disciplinary rationale for the research itself." The initial use of digital media enhances current practices, and we have developed new resources, tools and practices to transfer current analogue practices to digital tools, for example, to build archives, use mapping software and add images to narratives. That process, however, gradually raises issues and exposes inconsistencies that lead towards an inquiry into first principles. These inquiries today range from long-accepted assumptions and categories to the purpose and audience. The opportunity is the possibility of using other ways to know about and represent the past. In short, O'Donnell's law reinforces the historicity of history. Digital media punctuated the end of the twentieth century and encourages a re-examination of the past 100 years and more of modern historical practice.

My third connection comes from my training as an historian of Japan, the Orient, the exotic. Like the previous two points, questions about twentieth-century historiography need not invoke the digital. This issue of the non-west (a question that long vexed scholars throughout the world during the twentieth century) made it possible for me to be at this conference where this article was presented. On the one hand, the synchronisation of the world according to a single history includes Japan within the conversation. But on the other hand, this synchronisation is a problem. Despite the rise of a global notion - the increasing inclusion of non-western places, issues and concepts into history - that history still maintains the framework of the west and the rest. The "rest", exalted or not, are placed in some position temporally behind the west. Here, I believe, there is a similarity to seventeenth-century France. Michel de Certeau describes the historian's role: "he [the historian] too has received from society an exorcist's task. He is asked to eliminate the danger of the other."4 If we are to better understand our lives as global, then we need to find other notions of time and space - beyond chronology and the nation-state - to represent the complex dynamics that had operated and currently operate.

Finally, this desire to change history, or whether history is in a state of crisis, is an old issue. But here I will cite two recent books, Hartog's Regimes of Historicity and Eelco Runia's Moved by the Past. Hartog sees our current state of presentism as a rift between experience and expectation; the end (around 1989) of two centuries of a progressive, linear temporality, which has yet to find a replacement. Runia opens his call for greater discontinuity in historical thinking with the provocative (for historians) statement that "historians don't think". He points to the premium placed on sorting and organising in history as opposed to "wilfully making a mess". Both see the end or limits of the dominant understanding of our discipline that have developed over the past two centuries. Neither invokes digital media, but the similar desire for a different history brings out the potential of digital media for conceptual change and also requires that we challenge the existing practices and understandings. Where do we go from here? My hope is that digital media will help us "make a mess" and reduce the rift between experience and expectation. 


\section{4}

This essay is based on my project 1884 (1884.ucsd.edu), which started over a decade ago, that explores the use of digital media (at that time, html) to conceive of and write history as a born-digital piece. ${ }^{5}$ I have thus far failed to write that born-digital piece, but my journey (more meandering around and getting lost) has taken me to many first principles of history and has shown me how much I failed to understand pasts and history in my previous work. Nevertheless, it has been a pleasurable journey, this wandering around and exploring other modes of conceiving our pasts beyond the confines of history.

Choosing a year is intended to raise questions about time, especially chronology. I chose 1884 not for any particular reason or significance - it is 100 years prior to George Orwell's Nineteen EightyFour. In a sense, 1884 in the western Pacific has more "events" than I would like, but still, in standard chronologies of Japanese history, entries for this year are sparse. ${ }^{6}$ Here, we have just raised a first principle, that of eventfulness. ${ }^{7}$ More important than significance is the position as a moment of transition, what Reinhart Koselleck called a Sattelzeit. Meiji 17, as the year is known in the Japanese calendar, is 16 years after the surrender of the Tokugawa bakufu or shogunate to an alliance of samurai that brought about the Meiji ishin (restoration) and six years prior to a constitution establishing a constitutional monarchy, a modern Japan. It was a transition period following a series of reforms in the early 1870s that changed the reckoning of time and the organisation of space on the archipelago in a way that was revolutionary. The ishin as restoration (the normal translation) suggests an originary moment (the event), an exalted, but dead past that begins the transformation to a known future, modern Japan. ${ }^{8}$ The ishin as revolutionary opens up the possibility for numerous happenings, sometimes chaotic and conflicting. By focusing on this in-between year, things previous and some not yet, I hope to explore the very formation of these categories of old and new and to explore a different way to think about change and transformation beyond the linear and celebratory narratives (of western systems) that are the rationale for and have beset non-western nation-states.

Much of this article builds on my inquiry into what kind of history is possible without chronology. I have written about this elsewhere; it is an essay that argues for historians to reengage with time.? Here I will simply invoke one of my favourite historians, Certeau, who decades ago called chronology an "alibi of time". ${ }^{10}$ Hartog, too, builds his meditation on the same essay. ${ }^{11}$ My inquiry, which combines historiography with digital media, opens up the possibility of nonlinear connections: recursivity, feedback loops, emergence and layers of temporality.

The empirical base of this study is a database of recorded happenings, centred around the archipelago as it was becoming Japan. Scholars of new media, such as Lev Manovich and Azuma Hiroki, talk about the digital age as that organised around databases as opposed to linear narratives. ${ }^{12}$ Manovich and Azuma see the elevation of the database as a new, interactive and less linear way of knowing. Yet this perspective downplays the centrality of the database in the formation of science in the nineteenth century. Geoffrey Bowker points out that the database was key to the formation of a single archival format that ordered information about the world. ${ }^{13}$ All information was organised according to regular grids. This database is built on standards, universals and abstractions (such 
as Newtonian absolute time and absolute space), that are separated from and encompass human variability. The goal was order, regularity and to conquer nature. Human variability interfered. The key to reconceiving history is not the database itself (variability and unevenness exist within linear narratives), but one that does not operate according to the fixed (more accurately, anachronistic) categories that have served as the basis of this archive since the nineteenth century.

The use of recorded happenings is intentional; it is to build on traces prior to the filters that determine whether they are fact, information or irrelevant. For example, in newspaper accounts we can see a world where past and present are not separate. Images use inherited understandings to depict current issues, a ghost calendar continues to haunt the authorities which had imposed the Gregorian solar calendar eleven years earlier, a tengu (magical figure) saves a boy, there is a report about flying cats, edible dirt saves a people in a village on the brink of starvation, a monk was reportedly bewitched by a fox god, and a girl was reportedly spirited away (and found). These are stories we now called folklore and superstition, but were very much of the present.

But along with this world where the past and present were indistinguishable, others identified these same objects, things and ideas to be old-fashioned. Inoue Enryō, the ghost professor (as in ghostbuster), toured the archipelago to collect stories of wonder so that he could categorise them and explain away such phenomena scientifically. ${ }^{14}$ The former reckoning of time, the tempo calendar (lunar), was replaced by the solar calendar, thus making lunar-based time-reckonings old-fashioned. (Much of the archipelago, especially the rural areas, continued to use the lunar calendar even after the Second World War.) Many second-hand shops popped up (as antique shops) to sell merchandise from temples and the former elite who, having lost their stipends, needed to sell objects that had lost their former value as status objects and sacred icons (and gained new value among foreigners looking for orientalia - objects that show the living past).

On the international level, Japan participated in the International Meridian Conference in Washington DC. It was the only Asian presence of the 26 participating countries; the three other non-western countries were Hawaii, Liberia and Turkey. As a result of this conference, the world was divided into 24 time zones, the Meridian was located at Greenwich, the meter was adopted, and the beginning of the day was located opposite Greenwich - 180 degrees - at what is now the International Dateline, thereby confirming Asia as the east, the Orient (or original stage of world history).

At the same time, the old was separated into the dead past and heritage. Sumo wrestling was revived, famous sites became parks and laws were passed, beginning in 1871, to survey temples and shrines and, in 1884, to regulate the sale of antiques. A concern for heritage, then, is not a reaction against western encroachment, but a recognition of the changing valuation of time. These new heritage sites became spatialised time; they indicate the remapping of these newly valued pasts onto an emerging collective singular.

An historical past was also being formulated. Shigeno Yasutsugu, the director of the new Office of Historiography, challenged the veracity of many stories that had been accepted as history (as historia magistra) and is nicknamed Dr Obliterator for his work disputing what had been historical truths. On the other hand, Okakura Kakuzō and Ernest Fenollosa, on a government survey of 
temples and shrines, made "eventful" their "discovery" of a kannon in the Yumedono of the Hōryū$\mathrm{ji}$; they formed the Nihonga shinkyōkai, a society to promote Japanese art, and became central figures in the formulation of a Japanese art history. Their narrative is based on the Buddhist icons and screen paintings like those found in the "antique" shops or stored in temples. In both above cases, the value of texts and objects that had been part of the present were dated and became part of the past - literature or art - transforming them into data of a national past. This formulation of a history of Japanese art both increased the value of the "antiques" westerners were collecting and made it more difficult to buy and export the new art pieces, which now were artefacts of heritage.

\section{Hints of a multilinear history}

From this partial inventory, we see a heterogeneity of things, centralising tendencies and happenings that belie a linear transformation as well as a chronology in which little happened. This year is empty of "important" events if the only criteria is the political and economic development of the new nation-state. Each happening embeds meaning within a particular place or moment, showing isolated or overlapping temporalities. The past in this case is a layering of different temporalities: that in which place and immediacy is preeminent, in contrast to our current practice of increasingly incorporating objects and people into a singular narrative of national becoming. The latter (as well as the political leaders who describe themselves as the "new", the moderns) would see this as a chaotic impediment, the old must give way to the new. Any trace of old relegates those so categorised to backwardness.

Here, the database raises questions about standard historical narratives. The fragmentation of inherited knowledge into different dead pasts, the forgotten past, outmoded past, heritage and tradition serve a political purpose (of which the new field of history was a part). The relegation of ghost stories to the category of superstition and later the field of folklore served the political desire of the leaders and their policy of building a strong nation-state by educating (civilising) the masses. Yet we see a spike between 1882 and 1885 of articles in newspapers (a new media that is part of the transition to a modern society) about mysterious, ghostly sightings. ${ }^{15}$ At the very least we see the coexistence, the layering, of different temporalities. On the one hand, this shows the continuation of an epistemology in which pasts and present are not separated. Perhaps the ghostly serve as a form of historia magistra among the commoners. On the other hand, these reports coincide with a deflationary economic policy, initiated in 1881 and lasting through 1884, debtor rebellions and revolutionary upheaval. ${ }^{16}$ The result of this economic policy was to severely curtail popular investment, force the bankruptcy of many small landowners, increase tenancy and expand the pool of commodified labour. The Matsukata deflation did stabilise the national economic system for largescale investment. Perhaps ghost stories are not evidence of backwardness and ignorance but, instead, are an indication of the destabilisation of society and the people's effort to make sense of their insecurity and uncertainty using the knowledge system with which they were most comfortable. The database has the potential to move history away from its implicit connection to hierarchical structures. In this history we see Manuel DeLanda's division between meshwork societies and hierarchical societies. On the one hand are the many petty bourgeoisie seeking opportunity in the 
new society but, on the other, in the standard history we see suppression by a government intent on limiting opportunity and creating a compliant citizenry. ${ }^{17}$

A similar connection between history and hierarchy exists on the international level where a Hegelian world history places the Orient in the first stage of development. Not yet, backward, unchanging, childlike, imitator and follower are some of the adjectives common in twentieth-century histories of non-western places. Yet, Japan unified time in 1873 and synchronised its time with Greenwich in 1886; Germany unified time in 1896; France adopted Greenwich time in 1911; and while railroads in the United States divided time into four timezones in 1883, it did not become official US time until 1918. In this case, at least, Japan was less a late developer than a coeval participant. ${ }^{18}$

This comingling of inherited knowledge with the unfamiliar or the new is closer to current social science understanding of how people know and learn. Research on reading and learning, for example, shows that people internalise new information through the categories and systems that they know. Their minds are not blank hard drives (or to invoke John Locke, as "white paper, void of all characters, without any ideas"). ${ }^{19}$ Furthermore, in cognitive science the field of distributed cognition shows that knowledge and action is based on one's environment (social and physical) as well as what is in one's head. ${ }^{20}$ People know and retrieve information through a distributed field of their material environment, recent information and interlocutors. My suggestion above of the relationship between the ghostly and economic policy makes sense (not proved) if we understand that people operate through situated practices (or figured worlds), rather than through the discrete categories of modern (new, valued) and folklore (old, quaint). ${ }^{21}$

This raises a question of how things change and how historians describe that change. As suggested above, a history that uses chronological time emphasises the unfolding of the collective singular, the nation-state. In the name of change, the narrative of unfolding reinforces a form of stasis, the continuity of the existing system. This is evident in a statement by Georg Simmel that is crucial to any effort to conceive of a different kind of history. "The things that determine and surround our lives, such as tools, means of transport, the products of science, technology and art, are extremely refined. Yet individual culture, at least in the higher strata, has not progressed at all to the same extent; indeed, it has even frequently declined."22 We must recognise that history, as it developed, was oriented towards describing the tools, transport, science, technology and art of the newly formed collective singular. These have been key objects in the histories of modern nation-states. Yet, despite the many advances we have made to bring common people into history, we still operate within a structure that denigrates what Simmel calls individual culture. Simmel goes on to decry the result - the objectification of the mind and the deprivation of the soul. The relegation of ghosts to folklore is an occultation that facilitates that objectification. By uncritically using such tools, science and technology, the histories we write that emphasise the eventful and significant often unwittingly support this objectification.

A different way to think about change comes from complex adaptive systems. This concept focuses on simple units (often called agents), from which larger, increasingly complex units emerge. Movement and environment is just as important as the characteristics of the unit. Emergence depends 
on the nature of the interaction, adaptations that occur, the environment and experience. Because environment is so important, replicability is difficult.. ${ }^{23}$ This system strikes me as commonsensical to how my life operates, yet it has not been how we have written history. Here, we must recognise the situatedness of information whose meaning, when extracted and placed in a different setting (the creation of the modern archive and the historical "fact"), is often altered. We must also recognise the likelihood of different outcomes of similar processes. An important reason for this variability are the multiple temporal layers that coexist, sometimes connecting and morphing as they do, and at other times remain separate. Harder, perhaps, but certainly necessary if we are to recognise our current theories of social change are limited at best, and if we are to recover the human or Simmel's individual culture in our writing of histories.

I would like to end with an appeal to recover stories and storytelling in history. In the vocabulary of historiography, this can be one way to reformulate historia magistra in our modern histories, by quite simply incorporating the stories that bring pleasure to the research process but are not often included in monographs. It is more possible in the digital era where we are no longer limited to the text - a pdf in long or short form - as the principal form of communicating with others. Two quotes, both addressing twentieth-century historical practices are germane. First, Thomas Kuhn exposes the historical method, "in history, more than in any other discipline I know, the finished product of research disguises the nature of the work that produced it". ${ }^{24}$ Second, from Simmel again: "The deepest problems of modern life flow from the attempt of the individual to maintain the independence and individuality of his existence against the sovereign powers of society, and against the weight of the historical heritage and the external culture and technique of life."25 We hide the stories and de-emphasise or eliminate what Simmel describes as one of the "deepest problems of modern life".

The pleasure of research for many historians, myself included, is in the immersion in the sensibilities of another era. We enjoy searching for accounts of how others reacted when confronted by something new, especially chance, uncertainty and serendipity. These are often the personal stories, diaries, writings or records that embed "facts". We read many such accounts, place them into various categories and write them up according to the processes and frameworks of our present. This is where Kuhn is correct; the finished history hides "the work that produced it". We have generally eliminated one of the things that makes historical research so engaging, the stories that bring out understanding, ethics and uncertainty. Too often what is hidden are the acts of individuals and the techniques of life while sovereign powers and historical heritage are emphasised. The digital, as I have tried to describe it here, has the potential to remove this mask - recorded happenings are less filtered than fact, emergence allows for different ways to think about the relation of things and, what I have not discussed here, place (which I have described as a stoppage of time elsewhere) is not given or natural.

My current project is to unpack (dare we say deconstruct) the scholarly monograph, a compromised amalgam of conceptual structure, interpretation and data. I plan to adapt the idea of media mix (from Japanese anime) or what Henry Jenkins calls transmediation. ${ }^{26}$ It is a grouping of different media around the same character or story that creates an environment of interaction; each part is self-contained, but they also refer to and enhance each other. I plan to separate the concep- 
tual structure, a short book entitled History without Chronology, from a collaboratively researched and written history of the nineteenth-century western Pacific that examines the transition centred around Japan and a digital almanac of the stories on which the first two are built. Each can be read independently, but they will also point to each other. The first examines the limitations of chronological time in history; the second seeks to reconsider change and how a non-western place becomes modern; and the last offers stories, the happenings that both are at the basis of that change as well as many that lead nowhere. The first begs for examples of what a history without chronology might look like; a reinterpretation of change needs a conceptual structure for those interested in pursuing the problem. From the data, readers can wander around the myriad stories, but eventually they might ask for ways to make sense of such heterogeneous happenings and be drawn to the other texts. At least that is the idea.

In conclusion, my argument is not a replacement of some analogue for a digital form, but the use of the digital to question some of the first principles that we have naturalised over the past two centuries. We must recognise that history, as we have learned it, has been the culmination of the international liberal-capitalist system that has exploited nature and sought to incorporate all into the same homogenising system. We can use the technology not by succumbing to its mantra of metrics and measurement, but by recovering the heterogeneity of human beings and the place of chance, before the homogenising structures of our modern world.

\section{NOTES}

1 For two recent, open-access books on digital history, see Jack Dougherty and Kristen Nawrotzki, eds, Writing history in the digital age (Ann Arbor: University of Michigan Press, 2013) and David Armitage and Jo Guldi, The history manifesto (Cambridge: Cambridge University Press, 2014).

2 François Hartog, Regimes of historicity: presentism and experiences of time, trans. Saskia Brown (New York: Columbia University Press, 2015).

3 Daniel Paul O'Donnell, "A first law of humanities computing," Journal of Brief Ideas (13 Mar 2016). doi:10.5281/zenodo.47473.

4 Michel de Certeau, The possession at Loudun, trans. Michael B. Smith, forward Stephen Greenblatt (Chicago: University of Chicago Press, 2000), 227.

5 For an early description, see Stefan Tanaka, "New media and historical narrative: 1884 Japan," Performance Research 11/4 (2006): 95-104.

6 For a very different form or recording the past, see Hayden White's discussion on annalistic forms in "The value of narrativity in the representation of reality," in The content of the form (Baltimore: Johns Hopkins University Press, 1987), 5-11.

7 William Sewell defines the event as "that relatively rare subclass of happenings that significantly transforms structures". Logics of history: social theory and social transformations (Chicago: University of Chicago Press, 2005), 100.

8 Reinhart Koselleck, Futures past: on the semantics of historical time, trans. Keith Tribe (Cambridge: MIT Press, 1985), 32-56. 
10 Michel de Certeau, "History: science and fiction," in Heterologies: discourse on the other, trans. Brian Massumi, forward Wlad Godzich (Minneapolis: University of Minnesota Press, 1986).

11 Hartog, Regimes of historicity, 2.

12 Lev Manovich, The language of new media (Cambridge: MIT Press, 2001), 225-43 and Hiroki Azuma, Otaku: Japan's database animals, trans. Jonathan E. Abel and Shion Kono (Minneapolis: University of Minnesota Press, 2009), 26-35.

13 Geoffrey Bowker, writes: "Creators [purveyors of science] stood outside regular space and time and imposed regular temporal order. In general, scientific work was seen as the imposition of a representative framework of regular space and time on social and natural time." Memory practices in the sciences (Cambridge: MIT Press, 2005), 40.

14 Inoue was called the yōkai hakase (ghost professor). See Gerald Figal, Civilization and monsters: spirits of modernity in Meiji Japan (Durham: Duke University Press, 1999), see esp. chap. 2.

15 Yumoto Kōichi, Chihōhatsu Meiji Yōkai Nyūsu (Tokyo: Kashiwa shobō, 2001).

16 Two activists who participated in the Gunma and Chichibu incidents declared Meiji 17 (1884) to be "Year one of the era of Free Self Rule". Roger Bowen, Rebellion and democracy in Meiji Japan (Berkeley: University of California Press, 1980), 246-47.

17 Manuel DeLanda, $A$ thousand years of nonlinear history (Brooklyn: Zone Books, 1997).

18 The recent research of Doug Howland argues that Japan was an active participant, not adopter, in the formation of international law during the second half of the nineteenth century. International law and Japanese sovereignty: the emerging global order in the 19th century (New York: Palgrave, 2016).

19 John Locke, An essay concerning human understanding, ed. and intro Peter H. Nidditch (Oxford: Clarendon Press, 1975), 104. For a good overview of recent work on reading, see Maryanne Wolf, Proust and the squid: the story and science of the reading brain (New York: Harper Perennial, 2008).

20 Edwin Hutchins, Cognition in the wild (Cambridge: MIT Press, 1995).

21 James V. Wertsch, Vygotsky and the social formation of mind (Cambridge: Harvard University Press, 1988). Dorothy Holland, "Figured worlds," in Identity and agency in cultural worlds (Cambridge: Harvard University Press, 1998).

22 Georg Simmel, The philosophy of money, ed. David Frisby, trans. Tom Bottomore and David Frisby (New York: Routledge, 1990), 448.

23 Gary William Flake, The computational beauty of nature: computer explorations of fractals, chaos, complex systems, and adaptation (Cambridge: MIT Press, 1998) and John H. Holland, Hidden order: how adaptation builds complexity (New York: Basic Books, 1995).

24 Quoted in Constantin Fasolt, The limits of history (Chicago: University of Chicago Press, 2004), 39.

25 Georg Simmel, "The metropolis and mental life," in The Blackwell city reader (Oxford: Wiley-Blackwell, 2002), 11.

26 Marc Steinberg, Anime's media mix: franchising toys and characters in Japan (Minneapolis: University of Minnesota Press, 2012) and Henry Jenkins, Convergence culture: where old and new media collide (New York: New York University Press, 2006). 